\title{
Research on Information Sharing in Supply Chain
}

\author{
Yinghua $\mathrm{Yu}^{1,2, a}$, Lixia Wang ${ }^{1, b}$ \\ ${ }^{1}$ Economics and Management School, Jilin Institute of Chemical Technology, Jilin 132022, China \\ 2 Business School, Jilin University, Changchun 130012, China. \\ acherry_yyh@163.com, b45448105@qq.com
}

Keywords: supply chain; information sharing; incentive mechanism; information asymmetry; information security.

\begin{abstract}
Information sharing is the critical factor to implement the total performance of supply chain. Information asymmetry in supply chain not only reduces the whole reaction speed, but increases cost. In this paper, some major types of sharing information in supply chain are discussed. Secondly, analyze the impact on obstacles to share information, including subjective and objective factors such as information disclosure risk, uneven distributed benefits, information-sharing cost, and structure instability, lack of talented person and lack of flexible hardware support. Finally, some comprehensive countermeasures are proposed such as leading incentive mechanism, enforcing information security, and building up a suitable information platform, selecting node enterprises carefully and integrating into big-data era.
\end{abstract}

\section{Introduction}

Supply chain management, which focuses on the integration of the overall node enterprises, has become one hotpot in the management research circle. Nowadays, competition is no longer just among single firms, but among the supply chains[1][2].Scope of the supply chain management now includes more than the operation activities within enterprises. It is believed that supply chain is a kind of a whole consolidation, integrated by core enterprise, suppliers, suppliers' suppliers, customers and customers' customers. Material flow, information flow, as well as fund flow could be controlled effectively by coordinating relationships among each entity in the supply chain, aiming to increase the overall reaction speed and decrease the overall cost. Early in1950s, Hau L. Lee, a Professor in supply chain management, proposed a theory called "Bullwhip Effect". The theory raised the following points as: in customer-centered supply chain management, order decision-making process in each member of the supply chain is usually based on the demand information from its direct downstream enterprises. But the information fluctuations from downstream to upstream along supply chain become more and more big. In other words, tiny demand fluctuation from market will cause huge uncertainties to manufacturers when making MPS, and these uncertainties will become more and more bigger along the supply chain. As the concept of "Bullwhip Effect" has great effect on collaboration efficiency and benefits in supply chain, many researchers have examined reasons as well as influence of it. Distorted information causes the inventory cost of every entity in supply chain go up constantly. It is believed that high level information-sharing among nodes enterprises is an efficient way to reduce "Bullwhip Effect"[3][4]. There is no doubt that the overall cost will decease and the overall efficiency will be improved, if all the node enterprises could share their information with others in the chain.

\section{Information Types in Supply Chain}

According to the sources, information in supply chain could be divided into three major types: (1)information offered by retailers. This kind of information is mainly about the customers and the actual market demands. Feedback information, customer accounts information as well as after-sale service information is also included. (2) Information offered by manufacturers. Information offered by manufacturers includes inventory information and order quantity information to upstream suppliers as well as information about production planning, production schedule, supply resource to 
downstream retailers. (3) Information offered by suppliers. Information offered by supplier comes from middle and downstream of the supply chain, including amount of supply, merchandise information, supply time, producing capability and producing schedule.

Information asymmetry in supply chain leads to more transaction costs, and sharing information can greatly reduce searching time for member enterprises cooperation. On the other hand, in operation process, the supply chain system produce a lot of information which is easy to stag in a node, hindering the normal operation of entire system. Information sharing can promote the flow of information and improve the efficiency of supply chain operation. Usually, the value of information-sharing includes: reducing inventory cost; reducing lead time and increasing inventory turnover; reducing total cost and improving working flow management effectively; improving customer loyalty. So if all types of information such as customers' demands, inventory, MPS, producing schedule could be shared in supply chain and each link could be connected tightly, then the overall performance would be improved.

\section{Impacted Factors of Information Sharing in Supply Chain}

The impacted factors of information sharing in supply chain could be divided into two broad categories: subjective factors and objective factors.

\subsection{Subjective Factors}

The critical reasons for the enterprises not willing to share information in the supply chain are some major subjective factors which are regarded as too risky, such as information disclosure, uneven distributed benefits and the cost of information sharing, etc.

\subsubsection{Information Disclosure Risk}

Information disclosure in the process of information sharing has seriously affected cooperation. It will not only cause the failure of information sharing, but even break partner relationship in supply chain. Information disclosure not only exists in the process of information sharing in supply chain, but is probably involved in the whole information transmission process, which leads to a serious operation barrier in supply chain. Imagine if a retailer shares some important financial information or market demanding information in his supply chain, but unfortunately the information is disclosed and his rival competitors make use of it that would be a nightmare. No one would like to undertake this kind of risk. To avoid the risk, is not to share.

\subsubsection{Uneven Distributed Benefits}

One supply chain includes many enterprises, and each one has different position and power. Each supply chain has one core enterprise, which could benefit from information-sharing mostly. By using sharing information, he could increase bargaining capability to dominate when negotiated with suppliers and retailers, which then makes the whole supply chain lack of fair. Also, if the information flow coming from downstream, such as the market demanding information, is critical important for upstream points in the supply chain, sharing information would give more benefit to the upstream enterprises. They could reduce their inventory and make a better producing schedule, etc. But for the downstream enterprises, the changing benefits are not as much as their upper partners in the chain. Although the overall performance of the supply chain improved, but benefits distributed are uneven. This is a big reason for the downstream enterprises not willing to share their information in the chain. In short, position decides how much benefit the enterprises could get in supply chain.

\subsubsection{Cost of Information Sharing}

As a rational decision maker, the enterprise ought to pursuit profit or competitive advantage. As a result, decision maker needs to compare the additional costs with benefits from sharing-information. Information collecting, processing and sharing means costs. Enterprises need to build information system as well as information network when they want to share information with others and get efficient information in their supply chain. If they want a good information system, a large amount of investment funds is essential, especially in the prior-period. When the nods in the supply chain are not stable enough, and some adjustment cost will arise. Furthermore, when "big data" becomes popular, some types of information are easy to be collected from some professional enterprises. But the data collected needs money and sometimes may be isolated. All of these will be big hindering for all the 
enterprises before they could see their prospective earnings form sharing information. The only way is to ensure all the members benefit more from supply chain, which will motivate them share information.

\subsection{Objective Factors}

\subsubsection{Instability of Supply Chain}

A critical characteristic of information is timeliness. Information volatility due to passing delay will aggregate pains of the up streams in supply chain. Supply chain is regarded as a systematic and integrated concept. Stability of supply chain is contributed to the whole performance. Here, stability not only refers to characteristic inside node enterprises, but also cooperation relationship among them. Usually, there lacks compelling force to members, and the structure of supply chain is instable[5]. That is, members in a supply chain would be changed. As information is located in every enterprise, if one enterprise leaves the chain, his own information as well as other members' prior sharing information would leave too. And then new member comes with his new information. That would be fine if the new member has better contribution to the whole chain, but it needs time and cost for adjustment.

\subsubsection{Lack of Talented Persons}

As the concept of supply chain has been popular for a long time, more and more enterprises realize the important role of talented persons in this field. Professionals in supply chain need understand information technology such as database and computer network as well as some management knowledge about supply chain. At present, while some universities and colleges have set some courses related to supply chain, they usually subject to certain aspects. For example, when talking about knowledge about supply chain, students often regarded as a part of logistics. Although there are some professions in some fields like logistics and information science, but scarcity in talented person with integrated capability still exists.

\subsubsection{Lack of Flexible Hardware supports}

Each member in the supply chain has his own technical support in principle, such as networks, database as well as E-business. But in fact, the needs of building information platforms are different. The central enterprises usually has advanced and integrated technology and equipment, and this kind of technical supports are easy to be find. But because of some restriction factors such as costs, many small and medium-sized enterprises have little needs to improve their technical platforms, and then the bottleneck emerges, which restricts the overall information sharing in the supply chain[6]. Furthermore, information standardization needs to be mentioned. When systems and modules in node enterprises are isolated from each other and lack of uniform standard, communication efficiency will greatly decrease, even if they each have high information levels.

\section{Way to share information in supply chain}

Some countermeasures against impacted factors mentioned above to share information in supply chain are listed below:

\subsection{Leading incentive mechanism}

One of the most important restrictions for information sharing is uneven benefit distribution in supply chain. Purpose of incentive mechanism in supply chain is to make all nodes profitable. Core enterprise must balance interests of all parties in the chain, and leading a reasonable incentive mechanism in accordance with cost-spending, risk-undertaking and relative position of each node[7]. For example, upstream enterprises reduce their inventory costs and out-of-stock losses by gaining more information from the chain, and get more benefit then. While downstream enterprises could not get corresponding benefit if the upstream enterprises do not let their supplying cost lower than before, which would discourage their motivation to share information. So, the incentive mechanism should encourage all the members to share their information by maximizing every node's profits if possible. For example, downstream enterprises are enabled to return selling and price incentive, while upstream enterprises are permitted to be involved in development. Leading effectively incentive mechanism could improve enthusiasm and also information-sharing level of every node, and finally achieve the overall maximize profit of the chain. 


\subsection{Enforcing information security}

Note that, from the perspective of each node enterprise, sharing too much information will increase risks, but sharing information not sufficiently may lead to uncertainty in demands as well as difficulty in making schedule. It is not easy to balance. While moral risk exists when sharing information with others. Strengthening the regulation and monitoring on information security management are needed on every node in supply chain in order to prevent information leakage. For example, signing non-disclosure agreement in principal-agent relationship could ensure the direction of information flow. Those who breach agreement must bear legal liability. At the same time, network security in and among enterprises in supply chain should also be strengthened to prevent malicious changes or information losses.

\subsection{Building up Suitable Information Platform}

Information platform is the basic of information sharing for enterprises, and whether platform is suitable is very important for each enterprise. It includes information system inside enterprise as well as public platforms between enterprises. The core enterprise in supply chain plays a critical role that ought to build and maintain the center platform for information sharing. In this way, other enterprises in supply chain have the motivation to share information by reducing their own costs, and at the same time information processing in the whole chain could be effectively and safely. Also, funds for platform-building should be shared and coordinated reasonably. Some researchers have found that information update frequency has effect on the stability of the system; especially the information in order and stock quantity fluctuation [8].As a result, suitable platform is the one that is easy to update and share some information.

\subsection{Selecting node enterprises carefully}

Some node enterprises in supply chain are lack of credit, which make other nodes suffer losses. Some nodes betray secrets without intension, owing to their lacks of management or low information level. Other nodes in supply chain then do not wish and dare to share information. In this case, core enterprise needs to establish a perfect assessment system to select node partners. The assessment indicators include credit level, operation and management capability, and information level, etc. If the supply chain structure is unstable, the selection would be careful and also account for other nodes' opinion. It is said that trust is the precondition and foundation of information-sharing.

\subsection{Integrating into big-data era}

In the era of big data, information resource requirements are continuously increasing. The operation and management of supply chain must adapt to the development of big data era .In big data era, the supply chain may connect more node organizations, at the same time, linking more information resources between the nodes. Also, requirements for information query, awareness and feedback are growing[9].Therefore, information management in supply chain management must realize docking with the needs of clients better to optimize and upgrade in the background of big data era. By relying on high quality and efficiency information, the supply chain could obtain value creation better .Information in big data could be good resource for supply chain. For the nodes, it is also an easy way to select useful information. By extracting, integrating and optimizing information from big data, every node could share more objective and targeted information, improving the overall information quality. In short, big data would contribute to promote the efficiency of information sharing in supply chain.

\section{Conclusion}

Sharing information could not only improve the efficiency, reduce total cost of the supply chain, but also promote trust between members and increase the whole response speed to market changes. There are some impacted factors of information sharing in supply chain including information disclosure risk, uneven distributed benefits, cost of information sharing, instability of supply chain, lack of talented person and flexible hardware support. The way to share information includes leading incentive mechanism, enforcing information security, building up suitable information platform, selecting node enterprises carefully and integrating into big-data era. To build an effective operation 
mechanism could improve performance of the supply chain and make all node enterprises "multi-win".

\section{References}

[1]. Cooper M C, Lambert D M, "Supply Chain Management: More than a New Name for Logistics", The International Journal of Logistics Management, vol.8, pp.1-11, 1997.

[2]. Lambert D M, Cooper M C, "Issues in Supply Chain Management", Industrial Marketing Management, vol. 29, pp. 65-83, 2000.

[3]. Lee H L and Whang S J," Information Sharing in Supply Chain", International Journal of Technology Management, vol.20, pp.373-387, 2000.

[4]. Xu K and Y Dong, "Towards Better Coordination of the Supply Chain", Transportation Research Part E: Logistics and Transportation Review, vol.37, pp.35-54, 2001.

[5]. Hall R, "Towards a Fusion of Formal and Informal Learning Environments: the Impact of the Read/Write Web”, Electronic Journal of e-Learning, vol. 7, pp.29-40,200.

[6]. Zhou H. and Berton WC., "Supply chain practice and information sharing," Journal of Operations Management, vol.25, pp. 1348-1365, 2007.

[7]. Li L. and Zhang H., "Confidentiality and information sharing in supply chain coordination,” Management Science, vol.54,pp.1467-1481, 2008.(In Chinses)

[8]. Gao J, "Incentive issues on information sharing between firms", Operation Research and Management Science, vol.5, pp. 245-250,2014.(In Chinses)

[9]. Wang Jing. Ling Tian. and Xun Wang, "The effect of information update frequency on the stability of supply chain", Systems Engineering, vol.3,pp.33-39,2010.(In Chinses) 